\title{
Compressif Lipoma of the Larynx: A Case Report
}

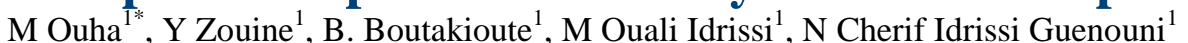

${ }^{1}$ Radiology department of AR-RAZI hospital UH Mohamed VI, Cadi Ayad University Marrakech, Morocco

DOI: $10.36347 /$ sasjm.2021.v07i04.007

| Received: 17.03.2021 | Accepted: 23.04.2021 | Published: 29.04.2021

*Corresponding author: M Ouha

Abstract

Case Report

Lipoma is a benign tumor of mesenchymal origin with a very rare occurrence in the upper aero digestive tract. Because isolated laryngeal lipoma symptoms are uncharacteristic and often has no systemic manifestation, clinical diagnosis is difficult. Accurate diagnosis on imaging such as computed tomography scan and magnetic resonance imaging scan can prevent unnecessary biopsy. Here we report a case of right false cord lipoma in a 76 years old man who presented with hoarseness for 4 months.

Keywords: Compressif, Lipoma, tumor, mesenchymal, Larynx.

Copyright $\odot 2021$ The Author(s): This is an open-access article distributed under the terms of the Creative Commons Attribution 4.0 International License (CC BY-NC 4.0) which permits unrestricted use, distribution, and reproduction in any medium for non-commercial use provided the original author and source are credited.

\section{INTRODUCTION}

Lipomas are the most common benign soft tissue tumors [1]. This tumor is not rare in the head and neck ( $\backslash 15 \%$ of all lipomas) [2, 3]. But they very rarely occur in the upper aero-digestive tract (larynx, hypopharynx) where they represent $0.6 \%$ of all benign neoplasms $[4,5]$. The symptoms depend on the size and location of the lipoma [6]. They may appear as a pseudo-cystic or pedunculated mass [7].

We report a case of laryngeal lipoma in a patient who presented dyspnea and stridor for 4 months that worsened gradually which prompted him to consult the emergency room.

\section{CASE REPORT}

A 76-year-old man with no pathological history presented to us with a complaint of dyspnea for 4 months with a stridor and dysphonia which was progressively worsening for the past week associated with intermittent shortness of breath leading to a tracheotomy in the ER.

On clinical examination, there was dyspena with stridor and respiratory distress. Computed tomography (CT) of the neck demonstrated a fatattenuating lesion (approximately - 55 Hounsfield units) measuring approximately $11 \times 12 \times 31 \mathrm{~mm}$ within the larynx, deep to the mucosal layer of the right vocal folds, resulting in almost total filling of the laryngeal lumen. A tracheotomy was performed and the patient.

\begin{abstract}
The patient underwent an endoscopic examination under anesthesia and biopsy. Intraoperatively, noted fullness superior to the right false cord, smooth surface with normal mucosa. Right true cord, left false cord and left ventricle were normal. Excision made after cautheterization of the implantation base, and yellowish soft tissue seen which appears to be fatty tissue. Histopathological examination confirmed the diagnosis of lipoma. No complications occurred during the postoperative period.
\end{abstract}

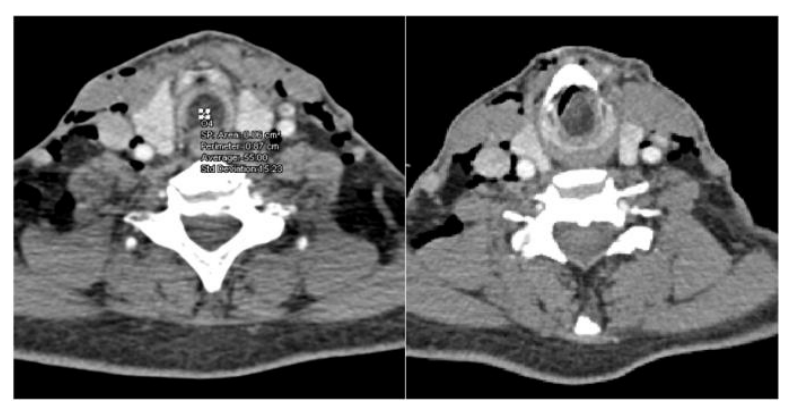

Fig-1: Axial reconstruction of CT scan with contrastenhancement shows an expansive, oval mass (white arrows), well-defined and regular margins, encapsulated, with frankly lipomatous density (-55 UH), exerting compression on larynx with a markedly narrowed lumen

\section{DISCUSSION}

Lipomas are benign, slow-growing primary mesenchymal tumours, which represent $4-5 \%$ of all benign tumors in the body [8]. They are more frequent in the trunk and limbs where subcutaneous fatty tissue is abundant. It has been estimated that $13-15 \%$ of 
lipomas occur in the head and neck region. The upper aero-digestive tract is a very rare localization $[9,10]$.

Laryngeal lipomas, which represent only $1 \%$ of all lipomas, are classified into extrinsic and intrinsic tumors. Extrinsic lesions are located in the posterior aspect of the larynx, pyriform sinus, and lingual surface of the epiglottis, while intrinsic tumors are located in the false vocal cord, laryngeal surface, aryepiglottic folds, and subglottic larynx [11].

Lipomas can be varied in shapes and sizes. Endoscopic appearance of lipoma is varied ranging from submucosal mass to pedunculated intraluminal projection, so clinical lipoma can be confused with other benign lesions such as retention cyst or laryngoceles [12].

Imaging provides a key role in diagnosis. On CT, lipomas appear as homogeneous lesions that are low in attenuation. Magnetic resonance imaging is preferred due to more accurate examination of the soft tissue, allowing for better visualization of a pedicle if present, of its extension in para-laryngeal and parapharyngeal spaces and its anatomical relationship with surrounding structures [7] .Adipose tissue is visualized as bright on T1-weighted imaging (T1WI) and will suppress on fat-saturated sequences [13].

There are four main differential diagnoses when evaluating fatty lesions of the larynx: Lipoma, liposarcoma, lipoblastoma, and hibernoma [14]. Differentiating liposarcomas and lipomas on imaging can be challenging due to subtle findings that may favor a liposarcoma [15]. Hemorrhage and necrosis are suggestive of liposarcoma, while complete fat suppression, lack of septations, and no enhancement favor the diagnosis of lipoma [15, 7]. Angiography might aid in differentiation due to hypervascularity in liposarcomas [7]. Definitive diagnosis is based on histopathology. Adipocytes of varying sizes as well as macrophages are suggestive of benign lipomas, while lack of macrophages and variation of adipocytes suggest liposarcoma over lipoma [15].

A lipoblastoma is a rare, benign tumor that arises from embryonic white fat but can look like liposarcoma on imaging; the lesion typically presents in infancy and early childhood, and most often occurs in the trunk and extremities.

A hibernoma is a lipomatous lesion seen in middle-aged patients, consisting of brown fat. On T1WI, a hibernoma is hypointense in comparison to subcutaneous adipose tissue and does not suppress on fat-saturated sequences [16, 17]. On CT, hibernomas are well-circumscribed lesions with attenuation between skeletal muscle and fat [17]. Significant difference between these lesions is observed on positron emission tomography/CT imaging due to brown fat's intense glucose metabolism and, therefore, avid fluorodeoxyglucose uptake. Under the microscope, hibernoma is described as multivacuolated fat cells of lobular pattern with prominent vascular supply.

The treatment of choice is total excision using conservative surgical removal when clinical symptoms are present [18]. The extent of the procedure depending on the size and site of a tumor. As there is a possibility of recurrence, lipomatous mass should be excised completely [18]. The small ones can be excised by endoscopic surgery, but external approach such as thyrotomy, transhyoid or lateral pharyngotomy is required for large masses [12].

\section{CONCLUSION}

Lipomas are benign mesenchymal tumours with rare localization in the upper aero-digestive tract. Our case highlights the point that laryngeal lipomas may if large in size, lead to compression on the surrounding cervical structures and, sometimes, to lifethreatening symptoms (dyspnoea, asphyxia). Imaging techniques (CT scan, MRI), are helpful for diagnosis, and in planning the best therapeutic strategy. Even though the lipoma is the most common fatty lesion within the head and neck, other diagnosis such as liposarcoma, lipoblastoma, and hibernoma must be considered.

\section{REFERENCE}

1. Rosai J. Rosai and Ackerman's surgical pathology e-book. Elsevier Health Sciences; 2011 Jun 20.

2. Megalamani SB, Gadag R, Raza A, Satish A. Lipomas of larynx: the rare entities. IJOPL. 2012;2(2):79-81.

3. Ashtiani MT, Yazdani N, Saeedi M, Amali A. Large lipoma of the larynx: a case report. Acta Medica Iranica. 2010:353-6.

4. Som PM, Scherl MP, Rao VM, Biller HF. Rare presentations of ordinary lipomas of the head and neck: a review. American journal of neuroradiology. 1986 Jul 1;7(4):657-64.

5. Barnes L, Ferlito A. Soft tissue neoplasms. In: Ferlito A, editor. Neoplasms of the larynx. First edition. London: Churchill-Livingstone. 1993: 265 304.

6. Sukumaran Y, Azrin N, Ping LS, Jane E, Madatang A. Laryngeal lipoma: a rare cause of hoarseness. Int J Otorhinolaryngol Head Neck Surg. 2019; 5:191-2.

7. De Vincentiis M, Greco A, Mascelli A, Soldo P, Zambetti G. Lipoma of the larynx: A case report. Acta Otorhinolaryngol Ital. 2010; 30:58-63.

8. Enzinger FM, Weiss SW. Benign lipomatous tumours. In: Enzinger FM, Weiss SW, editors. Soft tissue tumours. Third edition. St Louis: Mosby. 1995: 381-430.

9. Persaud RAP, Kotnis R, Ong CC. A rare case of a pedunculated lipoma in the pharynx. Emerg Med J. 2002; 19:275-6. 
10. Jungehulsing M, Fischbach R, Eckel HE. Rare benign tumors: laryngeal and hypopharyngeal lipomata. Ann Otol Rhinol Laryngol. 2000; 109:301-5.

11. Zakrzewski A. Subglottic lipoma of the larynx. (Case report and literature review). J Laryngol Otol. 1965; 79:1039-48.

12. Ashtiani MTK, Yazdani N, Saeedi M, Amali A. Large lipoma of larynx. A case report. Acta Medica Iranica. 2010;48(5):353-6.

13. Burkes JN, Campos L, Williams FC, Kim RY. Laryngeal spindle cell/pleomorphic lipoma: A case report. An in-depth review of the adipocytic tumors. J Oral Maxillofac Surg. 2019; 77:1401-10.

14. Okromelidze L, Middlebrooks EH, Bhatt AA. Lipoma of the larynx and other differential diagnoses. J Clin Imaging Sci. 2019; 9:51.
15. Kodiyan J, Rudman JR, Rosow DE, Thomas GR. Lipoma and liposarcoma of the larynx: Case reports and literature review. Am J Otolaryngol. 2015; 36:611-5.

16. Burt AM, Huang BK. Imaging review of lipomatous musculoskeletal lesions. SICOT J. $2017 ; 3: 34$.

17. Greenbaum A, Coffman B, Rajput A. Hibernoma: Diagnostic and surgical considerations of a rare benign tumour. BMJ Case Rep. 2016; 2016:bcr2016217625.

18. Özmen CA, Nazaroğlu H, Yildirim M, Akay HO, Bayrak AH. A rare cause of dysphonia: laryngeal lipoma: Differential diagnosis. Turkiye Klinikleri J Med Sci. 2009;29(6):1789-91. 